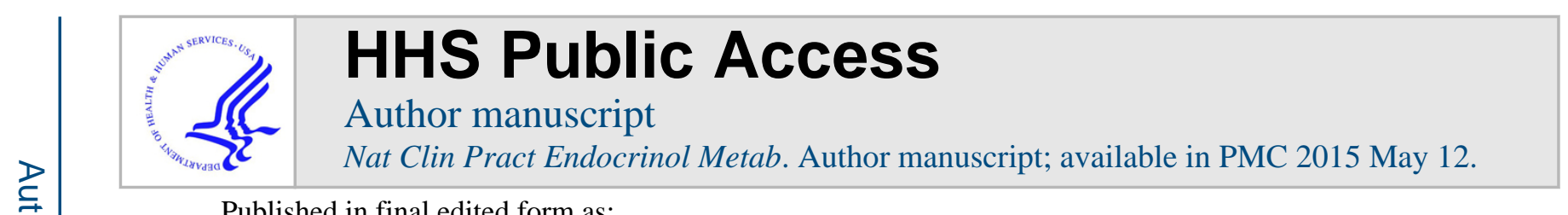

Published in final edited form as:

Nat Clin Pract Endocrinol Metab. 2007 October ; 3(10): 696-704. doi:10.1038/ncpendmet0616.

\title{
The metabolic syndrome in women
}

\author{
Rhonda Bentley-Lewis ${ }^{*}$ [Instructor in Medicine], \\ Harvard Medical School, and Associate Physician in the Division of Endocrinology, Diabetes, and \\ Hypertension at Brigham and Women's Hospital
}

Katherine Koruda [Clinical Research Assistant], and

Division of Endocrinology, Diabetes and Hypertension at Brigham and Women's Hospital

Ellen W Seely [Associate Professor of Medicine]

Harvard Medical School, Boston, and Director of Clinical Research for the Endocrinology, Diabetes and Hypertension Division at Brigham and Women's Hospital, Boston, MA, USA

\section{SUMMARY}

The metabolic syndrome is estimated to be present in 47 million US residents with a similar ageadjusted prevalence in men (24\%) and women (23\%). The consideration of various metabolic risk factors as a single entity in the metabolic syndrome provides clinicians with a tool by which they can identify a population at increased risk for type 2 diabetes mellitus and increased cardiovascular morbidity and mortality. Cardiovascular disease is the leading cause of mortality in women in the US. To reduce the risk of cardiovascular disease, efforts have focused on modifying the metabolic risk factors that constitute the metabolic syndrome: abdominal obesity, dyslipidemia, glucose intolerance, and hypertension. In addition, because of several circumstances specific to women, including pregnancy, polycystic ovary syndrome, oral contraceptive therapy use, and menopause, there are special considerations regarding risk factor identification, modification, and clinical management. This article provides a review of diagnostic and therapeutic issues that clinicians should consider when caring for women at risk for developing or diagnosed with the metabolic syndrome.

\section{Keywords}

metabolic syndrome; obesity; pregnancy; polycystic ovary syndrome; women

\section{INTRODUCTION}

The metabolic syndrome is a combination of risk factors, including abdominal obesity, dyslipidemia, glucose intolerance, and hypertension. The clustering of these factors is often attributed to Gerald Reaven, who popularized the term 'Syndrome X' in $1988 ;{ }^{1}$ however, these factors have been investigated in various combinations for more than 80 years. ${ }^{2}$ The aggregation of these features into a single entity provides clinicians with a tool by which

(C) 2007 Nature Publishing Group

*Correspondence Harvard Medical School, Brigham and Women's Hospital, Division of Endocrinology, Diabetes, and Hypertension, 221 Longwood Avenue, Boston, MA 02115, USA rbentleylewis@partners.org. 
they can identify a significant segment of the population at increased risk for developing type 2 diabetes mellitus (T2DM) ${ }^{3}$ as well as increased cardiovascular morbidity and mortality. 4,5

Cardiovascular disease (CVD) affects 42.1 million women over 20 years of age in the US and is the number one cause of mortality in women. ${ }^{6}$ According to the Heart Disease and Stroke Statistics 2007 Update, 1 in 30 female deaths could be attributed to breast cancer, whereas one in 2.6 women died from CVD. ${ }^{6}$ Data have shown that diabetes ${ }^{7}$ and hyperglycemia ${ }^{8}$ have poorer prognostic implications for CVD mortality in women than in men, even after adjusting for age and other CVD risk factors. The etiology of this differential impact of diabetes on the basis of gender is unclear; however, one explanation could be the high prevalence of the metabolic syndrome in female diabetic populations. An analysis of newly diagnosed patients with T2DM revealed that $82.9 \%$ met the National Cholesterol Education Program's Adult Treatment Panel III (ATP III) criteria for the metabolic syndrome at the time of T2DM diagnosis, and a significant majority of these were women rather than men $(89.9 \%$ versus $78.2 \% ; P<0.001) .{ }^{9}$

Studies have associated the metabolic syndrome with an increased risk for CVD and have shown that this risk is even greater among women than among men. ${ }^{10}$ When examining the ability of ATP-III-defined metabolic syndrome to predict cardiovascular mortality in the San Antonio Heart Study, hazard ratios in women were 4.65 (95\% CI 2.35-9.21) and in men 1.82 (95\% CI 1.14-2.91). ${ }^{11}$ This gender difference in risk was also observed in the Atherosclerosis Risk in Communities investigation, revealing hazard ratios of 2.05 (95\% CI $1.59-2.64)$ in women and 1.46 (95\% CI 1.23-1.74) in men.

In addition to gender differences in metabolic syndrome prevalence and CVD risk, there are gender-specific issues to consider in the metabolic syndrome. This Review will examine modifiers of the metabolic syndrome that are unique to women: pregnancy, lactation, gestational diabetes mellitus (GDM), preeclampsia, polycystic ovary syndrome (PCOS), hormonal contraceptives, and the menopause. Additionally, an overview of clinical management approaches specific to women will be addressed.

\section{DEFINITION OF THE METABOLIC SYNDROME}

The metabolic syndrome is defined by different criteria by several organizations including the World Health Organization, ${ }^{12}$ the European Group for Study of Insulin Resistance, ${ }^{13}$ the ATP III, ${ }^{4}$ the American Association of Clinical Endocrinologists, ${ }^{14}$ the International Diabetes Foundation, ${ }^{15}$ and the recent American Heart Association (AHA) and National Heart, Lung, Blood Institute update of the ATP III criteria. ${ }^{5}$ The various definitions exist because of differing opinions on the thresholds that should be used for specific criteria, such as blood pressure or fasting glucose levels. In addition, there is a lack of consensus on which components are fundamentally necessary and most clinically relevant for diagnosis. All of the definitions nonetheless include a measure of central obesity, glucose level, dyslipidemia, and hypertension. The focus of management is to achieve a normal level for each of the clinical and laboratory components that constitute the definition. 
Because the normal thresholds for some of the components vary by gender, and within each component there are gender-specific issues, the clinician must consider these issues in order to successfully prevent or manage the syndrome in women. Because the original ATP III definition has often been employed in epidemiological studies, ${ }^{16,17}$ we have chosen to focus this Review on the metabolic syndrome defined by these ATP III criteria (Table 1). ${ }^{4}$

\section{PREVALENCE OF THE METABOLIC SYNDROME IN WOMEN}

The metabolic syndrome was diagnosed in 47 million US residents according to US Census data from the year 2000. ${ }^{18}$ The age-adjusted prevalence was similar in men (24\%) and women (23\%); however, this gender equality was lost when comparing within ethnic groups. Although there were fewer white women with metabolic syndrome than white men, there are 57\% more African American women with the metabolic syndrome than African American men, and 26\% more Mexican American women with the metabolic syndrome than Mexican American men. ${ }^{18}$ When comparing National Health and Nutrition Examination Survey (NHANES) data obtained during 1988-1994 to data obtained during 1999-2000, the age-adjusted prevalence of the metabolic syndrome increased by $23.5 \%$ among women $(P=0.021)$ and $2.2 \%$ among men $(P=0.831)$. Therefore, the similarity in age-adjusted prevalence between men and women, regardless of ethnicity, will probably be lost with time. Notably, increases in blood pressure, waist circumference, and triglyceride levels were shown to be responsible for most of the increased metabolic syndrome prevalence among women. ${ }^{19}$

\section{COMPONENTS OF THE METABOLIC SYNDROME IN WOMEN}

Although the individual components that define the metabolic syndrome are the same in women and men, there are gender differences in how these components manifest in women as well as how they impact CVD risk in women (Box 1).

\section{Waist circumference}

Obesity has been steadily increasing in prevalence in the US for several years. ${ }^{20}$ Data from NHANES collected during 2003-2004 revealed that 32.2\% of Americans over 20 years of age were obese (BMI $\geq 30 \mathrm{~kg} / \mathrm{m}^{2}$ ). The prevalence of obesity among men increased significantly from $27.5 \%$ during $1999-2000$ to $31.1 \%$ during 2003-2004, but there was no significant change in obesity among women during these same time periods; prevalences were $33.4 \%$ and $33.2 \%$, respectively. From 1999-2000 to 2003-2004, however, the prevalence of extreme obesity (BMI $\left.\_40 \mathrm{~kg} / \mathrm{m}^{2}\right)$ increased among women $(6.3 \%$ versus $6.9 \%)$ but decreased among men (3.1\% versus $2.8 \%)$.

There were also gender differences in obesity prevalence by ethnicity. Non-Hispanic white women had a lower prevalence of overweight or obesity (BMI $>25 \mathrm{~kg} / \mathrm{m}^{2}$ ) than nonHispanic white men (58.0\% versus 70.6\%); Mexican American women had a similar prevalence to Mexican American men (75.4\% versus 76.1\%); and non-Hispanic black women had a greater prevalence than non-Hispanic black men (81.6\% versus $69.1 \%)$. 
Although obesity is clinically defined by BMI, data suggest that a more accurate reflection of true metabolic risk is central adiposity, assessed clinically by waist circumference measurement. The metabolic syndrome is characterized by a waist circumference greater than $102 \mathrm{~cm}$ in men and $88 \mathrm{~cm}$ in women by ATP III criteria. ${ }^{4}$

Waist circumference has also been shown to directly predict the metabolic syndrome. ${ }^{21}$ During 1988-2004, the age-adjusted prevalence of abdominal obesity increased from $29.5 \%$ to $42.4 \%$ among men $(P<0.001)$ and from $47.0 \%$ to $61.3 \%$ among women $(P<0.001){ }^{22}$ This trend is disconcerting because data from the San Antonio Heart Study suggested that increases in BMI and waist circumference increase the risk of developing the metabolic syndrome in women to a greater degree than in men. ${ }^{21}$ In fact, among individuals with BMI $230 \mathrm{~kg} / \mathrm{m}^{2}$ compared with those with BMI $<25 \mathrm{~kg} / \mathrm{m}^{2}$, the odds ratio for developing the metabolic syndrome was 3.7 in men but 8.3 in women. If waist circumference is $>102 \mathrm{~cm}$ in men rather than $<94 \mathrm{~cm}$, or $>88 \mathrm{~cm}$ in women rather than $<80 \mathrm{~cm}$, the odds ratio for developing the metabolic syndrome is 2.8 in men and 5.9 in women. ${ }^{21}$

\section{Dyslipidemia}

Women have a greater dyslipidemia-associated risk for coronary artery disease than men; this dyslipidemia is characterized by low levels of HDL cholesterol, small particle sizes of LDL cholesterol, and high triglyceride levels. ${ }^{23}$ Premenopausal women have higher HDL levels than similarly aged men; consequently, premenopausal women are less likely to satisfy the HDL criterion for diagnosis of the metabolic syndrome. Although triglyceride levels are associated with coronary artery disease and increase with age in men and women, the increase is greater in men than in women; however, elevated triglyceride levels have a greater impact on coronary artery disease risk in women than in men, especially in the setting of low HDL levels. ${ }^{24}$

\section{Hypertension}

Hypertension increases the risk of coronary heart disease, stroke, and renal disease in women as it does in men. Congestive heart failure is, however, more commonly seen as a consequence of hypertension in women even after adjustment for other risk factors. ${ }^{25}$ The prevalence of hypertension increases with aging in both women and men. At younger ages, the prevalence of hypertension is greater in men than in women but after the menopause, the prevalence of hypertension in women exceeds that in men. ${ }^{26}$

'White coat hypertension' (high blood pressure in the physician's office but not by 24-h monitoring) has been shown to confer an increased risk of CVD and is more commonly reported in women than in men. ${ }^{27}$ Consequently, this might contribute to a greater prevalence of metabolic syndrome diagnosis among women when the blood pressure criterion is included. Additionally, the hemodynamic profile of higher cardiac index (the body surface area-adjusted measure of the amount of blood that leaves the heart in one minute) and heart rate with lower peripheral resistance is characteristic of hypertensive women as compared with hypertensive men. ${ }^{28}$ 


\section{Hyperglycemia}

Although fasting blood glucose is used in the definition of metabolic syndrome, there are data demonstrating that the glucose level after a glucose load is more commonly elevated than fasting blood glucose in women; the reverse pattern is seen in men. ${ }^{29,30}$ In addition, the post-glucose-load glucose level is predictive of cardiovascular death in women. ${ }^{31}$ Consequently, the use of fasting blood glucose might underestimate T2DM, impaired glucose metabolism, and the metabolic syndrome in women.

\section{UNIQUE MODIFIERS OF THE METABOLIC SYNDROME IN WOMEN}

There are several factors unique to women that can impact the prevalence and characteristics of the metabolic syndrome in women (Box 2); these factors will be discussed below.

\section{Pregnancy}

Pregnancy is a significant contributor to weight gain in women. Data reveal that $42 \%$ of women gain more than The Institute of Medicine's recommended amount of weight during pregnancy. ${ }^{32}$ These women have a significantly greater weight gain at 10-year follow-up than women who gained the recommended amount or less during pregnancy. ${ }^{33}$ Women who retained pregnancy weight at 6 months postpartum were $8.3 \mathrm{~kg}$ heavier at 10 -year follow-up, whereas women who lost their pregnancy weight were $2.4 \mathrm{~kg}$ heavier. These data suggest that multiparous women might be at increased risk for obesity and, subsequently, the metabolic syndrome.

Consistent with this concept are NHANES III data showing that the rate of metabolic syndrome increases with increasing parity $(P<0.0001) .{ }^{34}$ After adjustments for age, race, ethnicity, income, education, and additional sociodemographic, reproductive, and behavioral risk factors, the odds of metabolic syndrome increased $13 \%$ (95\% CI 6-20\%) with each additional child. After adjusting for BMI, the relationship was weaker, indicating the importance of increased weight in mediating this risk.

\section{Lactation}

Lactation can decrease a woman's risk for the development of the metabolic syndrome. The odds ratio for metabolic syndrome was decreased by $22 \%$ (95\% CI 1-39\%) among women with a history of breastfeeding for more than 1 month compared with women who did not breastfeed or breastfed for less than 1 month. ${ }^{34}$ A recent investigation of postpartum women in two large cohorts, the Nurses' Health Study (NHS) and the NHS II, revealed that an increasing duration of lactation was associated with a reduced risk of T2DM. ${ }^{35}$ Among women with a birth in the previous 15 years, for each additional year of lactation there was a $15 \%$ (95\% CI 1-27) decrease in the risk of diabetes among the NHS cohort and a decreased risk of $14 \%$ (95\% CI 7-21\%) among the NHS II cohort. These results remained significant after adjusting for covariates associated with T2DM development, such as family history of diabetes, diet, exercise, and BMI, although BMI slightly attenuated the effect. 


\section{Gestational diabetes mellitus}

Approximately $7 \%$ of all pregnancies are complicated by GDM, defined as glucose intolerance with onset or first recognition during pregnancy. A pregnancy complicated by GDM presents an increased risk for subsequent glucose intolerance and T2DM, ${ }^{36}$ as well as the metabolic syndrome. ${ }^{37} \mathrm{~A}$ review of the literature between 1965 and 2001 revealed progression from GDM to postpartum T2DM as high as $70 \% .^{36}$

Studies have shown an increased prevalence of the metabolic syndrome in women with a history of GDM compared with those without GDM..$^{37,38}$ This increased risk was primarily due to increased abdominal obesity and lower HDL levels. Women with a GDM history were more likely to have elevated C-reactive protein (a marker of inflammation) and triglyceride levels, even after adjusting for BMI, which placed them at greater risk for developing T2DM and CVD. ${ }^{37}$ GDM can, furthermore, unmask prepregnancy metabolic syndrome. ${ }^{39}$ A study of young, obese, premenopausal women revealed that those with a history of GDM were more likely than those without a GDM history to have the metabolic syndrome $(86.6 \%$ versus $73.5 \% ; P<0.001)$, T2DM $(93.4 \%$ versus $63.3 \% ; P<0.001)$, and CVD (15.5\% versus $12.4 \%$; adjusted odds ratio 1.85 [95\% CI 1.21-2.82]; $P=0.005) .{ }^{40}$

\section{Preeclampsia}

Preeclampsia complicates approximately $5 \%$ of pregnancies in the US. According to the National High Blood Pressure Education Program's working group, preeclampsia is defined as a systolic blood pressure of at least $140 \mathrm{mmHg}$ and/or a diastolic blood pressure of at least $90 \mathrm{mmHg}$ on at least two occasions at least $6 \mathrm{~h}$ apart and accompanied by proteinuria after the 20th week of gestation in women known to be normotensive before pregnancy. ${ }^{4}$

Increased prepregnancy BMI is an important risk factor for preeclampsia. ${ }^{42,43}$ In a systematic review of 13 cohort studies of approximately 1 million women, O'Brien et al. observed that the risk of preeclampsia doubled for each 5-7-unit increase in prepregnancy BMI. ${ }^{43}$ Women with high glucose, insulin, and triglyceride levels are more likely to develop preeclampsia; ${ }^{44}$ furthermore, women with a history of preeclampsia have greater insulin resistance ${ }^{45}$ and an increased incidence of hypertension ${ }^{46}$ when examined several years postpartum. There are also data suggesting an increased CVD risk in women with a history of preeclampsia, ${ }^{44}$ but definitive prospective studies are lacking.

\section{Polycystic ovary syndrome}

PCOS affects 6-7\% of premenopausal women, with estimates varying on the basis of ethnicity and environmental influences. ${ }^{47}$ There are currently no universally accepted criteria for the diagnosis of PCOS, but most definitions include the presence of oligoovulation, hyperandrogenism, hyperandrogenemia, and the exclusion of other medical disorders that might have similar presentations. ${ }^{48-50}$ PCOS has many characteristics similar to those of the metabolic syndrome. In fact, the prevalence of the metabolic syndrome in PCOS is approximately $43-47 \%$, which is twice as high as the prevalence in the agematched general population, even after adjusting for BMI. ${ }^{51}$ Although there are nonobese women with biochemical and ultrasonographic features of PCOS, obesity is a key component of the pathology associated with PCOS. ${ }^{52}$ 
The components of the metabolic syndrome most commonly present in PCOS are central obesity and low serum HDL levels; however, hypertension, increased fasting glucose levels, and impaired glucose tolerance are also commonly present. ${ }^{53}$ PCOS has been associated with an increased prevalence of dyslipidemia, which has been shown to be heritable among the sisters of women with PCOS. ${ }^{54}$ Moreover, there is an increased prevalence of metabolic syndrome in sisters of women with PCOS who manifested the PCOS phenotype compared with the unaffected sisters $(P<0.001) .{ }^{54}$ Additionally, women with PCOS have a higher risk of diabetes than women of similar BMI with regular menses. ${ }^{55}$ Finally, there are data supporting an increased risk of BMI-independent hypertension and an increased risk of CVD in women with PCOS compared with women who have regular menstrual cycles, but these findings are controversial. ${ }^{56}$

\section{Hormonal contraceptives}

Weight gain is often considered a side effect of combination oral hormonal contraceptives, but causality has not been established. ${ }^{57}$ Three prospective, randomized, ${ }^{58,59}$ and placebocontrolled $^{59}$ trials did not find evidence supporting a causal association between combination oral contraceptives or a combination skin patch and weight gain. ${ }^{57}$ Combined oral contraceptive pills can decrease insulin sensitivity and glucose tolerance, ${ }^{60}$ affect lipoprotein levels, ${ }^{61}$ and increase blood pressure. ${ }^{62}$ The combination of ethinyl estradiol with drospirenone, a mineralo-corticoid-receptor blocker, has not, however, been associated with hypertension and might even promote blood pressure lowering. ${ }^{63}$

\section{The menopause}

Although BMI increases with aging, the menopause does not seem to have a significant role in this increase ${ }^{64}$ The menopause does, however, promote a change in body fat distribution to increase central adiposity and subsequently enhance the likelihood of satisfying the metabolic syndrome criteria. In an ancillary study to the Study of Women's Health Across the Nation (SWAN), regular physical activity was found to reduce the tendency for weight gain and adverse changes in body composition and fat distribution that accompany aging and the menopause. ${ }^{65}$

Insulin resistance increases with age and with increased abdominal obesity, but it is unclear if the menopause per se modifies this increase. ${ }^{66}$ The menopause has been associated with an increased incidence of hypertension, lower HDL, and higher LDL levels. ${ }^{26,67}$ Although postmenopausal therapy with oral estrogens increases HDL levels, the use of estrogen has not been shown to decrease CVD risk in post-menopausal women when used for primary ${ }^{68}$ or secondary ${ }^{69}$ prevention.

\section{THERAPEUTIC OPTIONS FOR THE METABOLIC SYNDROME}

The AHA recently published evidence-based guidelines for CVD prevention in women. ${ }^{70}$

According to these guidelines, lifestyle interventions should be instituted, including smoking cessation, diet control, and exercise. Interventions targeted at the major risk factors, including hypertension, dyslipidemia, and diabetes mellitus, are also detailed in these 
guidelines. Data from the NHS revealed that healthy diet and body weight, and regular exercise were associated with a CVD risk reduction of $82 \% .^{71}$

In brief, lifestyle recommendations to decrease CVD risk include weight reduction and increasing physical activity, restriction of sodium intake, and diet modification. If blood pressure remains $\geq 140 / 90 \mathrm{mmHg}$, then pharmacologic therapy should be initiated. The approach to lipid-lowering and glucose control $\left(\mathrm{HbA}_{1 \mathrm{C}}<7 \%\right)$ also begins with lifestyle modifications followed by pharmacologic therapy if necessary.

Guideline recommendations of particular importance to women highlight that estrogen replacement therapy should not be used for primary or secondary prevention of CVD. Furthermore, aspirin is not recommended for women aged less than 65 years with a 'low risk' of CVD; by contrast, men in this age group benefit from aspirin.

Dietary recommendations for the prevention and treatment of the metabolic syndrome include low intake of saturated and transunsaturated fat; balanced carbohydrate intake prioritizing high dietary fiber, fruit, and vegetable sources; and eating low-fat dairy foods. ${ }^{72}$ Physical activity recommendations are available for the metabolic syndrome, including preexercise evaluation and how to optimally prescribe and monitor exercise regimens for patients with the metabolic syndrome that incorporate types and volume of exercise as well as aerobic and resistance activities. ${ }^{73}$ Additionally, recommendations for diet, exercise, and weight loss of initially $7-10 \%$ of baseline weight are provided by the AHA. ${ }^{5}$

Whereas most of the data on the benefit of CVD risk factor reduction were originally demonstrated in men, studies have now been performed in women. Lowering of blood pressure effectively reduces risk of CVD in women. ${ }^{74}$ The pharmacologic treatment of hyperlipidemia in women is beneficial for both primary ${ }^{75}$ and secondary ${ }^{76}$ prevention of heart disease. The Diabetes Prevention Program demonstrated that a reduction of approximately 5-7\% of body weight, achieved though diet and exercise, was associated with a $58 \%$ reduction in the onset of T2DM in both women and men. ${ }^{77}$

Women with PCOS or with a history of GDM or preeclampsia might also require interventions targeting the metabolic syndrome. Additionally, particular vigilance needs to be paid to women of childbearing age in the prescription of medications to treat the metabolic syndrome components. The use of angiotensin-converting-enzyme inhibitors during pregnancy has been associated with an increased risk of birth defects ${ }^{78}$ and neonatal renal failure. ${ }^{79}$ The use of angiotensin-2-receptor blockers during pregnancy has also been associated with neonatal renal failure. ${ }^{80}$ Additionally, the use of statin therapy has been contraindicated for use in pregnancy and even during child-bearing years because of concerns for fetal safety. ${ }^{81}$ A recent analysis of women who used statin therapy in the first trimester and continued through pregnancy did not, however, find evidence of congenital anomalies or increased risk to live-born infants. ${ }^{82}$ Notably, data from non-live births in this analysis limited the ability to formulate definitive conclusions regarding safety. ${ }^{82}$ 


\section{CONCLUSIONS}

Cardiovascular disease is a significant cause of morbidity and mortality in women.

Metabolic risk factors, such as those clustered in the metabolic syndrome, have been identified and are targeted in efforts to reduce the risk of developing CVD. Moreover, several of these risk factors have different prevalence rates in women compared with men and can be influenced by circumstances specific to women, such as pregnancy, oral contraceptive therapy, and the menopause. Consequently, clinicians face the challenge of being able to not only recognize but also intervene appropriately in these different settings to reduce CVD risk among women. Although lifestyle interventions should benefit all, clinicians need to be aware of pharmacologic treatment concerns for women of childbearing age.

\section{References}

1. Reaven GM. Role of insulin resistance in human disease. Diabetes. 1988; 37:1595-1607. [PubMed: 3056758]

2. Sarafidis PA, Nilsson PM. The metabolic syndrome: a glance at its history. J Hypertens. 2006; 24:621-626. [PubMed: 16531786]

3. Meigs JB, et al. Body mass index, metabolic syndrome and risk of type 2 diabetes or cardiovascular disease. J Clin Endocrinol Metab. 2006; 91:2906-2912. [PubMed: 16735483]

4. National Cholesterol Education Program. Executive Summary of the Third Report of the National Cholesterol Education Program (NCEP) Expert Panel on Detection, Evaluation, and Treatment of High Blood Cholesterol In Adults (Adult Treatment Panel III). JAMA. 2001; 285:2486-2497. [PubMed: 11368702]

5. Grundy SM, et al. Diagnosis and Management of the Metabolic Syndrome: An American Heart Association/National Heart, Lung, and Blood Institute Scientific Statement. Circulation. 2005; 112:2735-2752. [PubMed: 16157765]

6. Rosamond W, et al. Heart disease and stroke statistics-2007 update: a report from the American Heart Association Statistics Committee and Stroke Statistics Subcommittee. Circulation. 2007; 115:e69-e171. [PubMed: 17194875]

7. Lee WL, et al. Impact of diabetes on coronary artery disease in women and men: a meta-analysis of prospective studies. Diabetes Care. 2000; 23:962-968. [PubMed: 10895847]

8. Hu G, et al. Gender difference in all-cause and cardiovascular mortality related to hyperglycaemia and newly-diagnosed diabetes. Diabetologia. 2003; 46:608-617. [PubMed: 12750769]

9. Guzder RN, et al. Impact of metabolic syndrome criteria on cardiovascular disease risk in people with newly diagnosed type 2 diabetes. Diabetologia. 2006; 49:49-55. [PubMed: 16341841]

10. Sarafidis PA, et al. Gender disparity in outcomes of care and management for diabetes and the metabolic syndrome. Curr Diab Rep. 2006; 6:219-224. [PubMed: 16898575]

11. Hunt KJ, et al. National Cholesterol Education Program versus World Health Organization metabolic syndrome in relation to all-cause and cardiovascular mortality in the San Antonio Heart Study. Circulation. 2004; 110:1251-1257. [PubMed: 15326061]

12. Alberti KG, Zimmet PZ. Definition, diagnosis and classification of diabetes mellitus and its complications. Part 1: Diagnosis and classification of diabetes mellitus provisional report of a WHO consultation. Diabet Med. 1998; 15:539-553. [PubMed: 9686693]

13. Balkau B, Charles MA. Comment on the provisional report from the WHO consultation. European Group for the Study of Insulin Resistance (EGIR). Diab Med. 1999; 16:442-443.

14. Einhorn D, et al. American College of Endocrinology position statement on the insulin resistance syndrome. Endocr Pract. 2003; 9:237-252. [PubMed: 12924350]

15. Alberti KG, et al. The metabolic syndrome: a new worldwide definition. Lancet. 2005; 366:10591062. [PubMed: 16182882] 
16. Meigs JB, et al. Prevalence and characteristics of the metabolic syndrome in the San Antonio Heart and Framingham Offspring Studies. Diabetes. 2003; 52:2160-2167. [PubMed: 12882936]

17. Ford ES. The metabolic syndrome and mortality from cardiovascular disease and all-causes: findings from the National Health and Nutrition Examination Survey II Mortality Study. Atherosclerosis. 2004; 173:309-314. [PubMed: 15064107]

18. Ford ES, et al. Prevalence of the metabolic syndrome among US adults: findings from the third National Health and Nutrition Examination Survey. JAMA. 2002; 287:356-359. [PubMed: 11790215]

19. Ford ES, et al. Increasing prevalence of the metabolic syndrome among US adults. Diabetes Care. 2004; 27:2444-2449. [PubMed: 15451914]

20. Ogden CL, et al. Prevalence of overweight and obesity in the United States, 1999-2004. JAMA. 2006; 295:1549-1555. [PubMed: 16595758]

21. Han TS, et al. Analysis of obesity and hyperinsulinemia in the development of metabolic syndrome: San Antonio Heart Study. Obes Res. 2002; 10:923-931. [PubMed: 12226141]

22. Li C, et al. Increasing trends in waist circumference and abdominal obesity among US adults. Obesity (Silver Spring). 2007; 15:216-224. [PubMed: 17228050]

23. Legato MJ, et al. Gender-specific care of the patient with diabetes: review and recommendations. Gend Med. 2006; 3:131-158. [PubMed: 16860272]

24. LaRosa JC. Triglycerides and coronary risk in women and the elderly. Arch Intern Med. 1997; 157:961-968. [PubMed: 9140266]

25. Levy D, et al. The progression from hypertension to congestive heart failure. JAMA. 1996; 275:1557-1562. [PubMed: 8622246]

26. Burl VL, et al. Prevalence of hypertension in the US adult population. Results from the Third National Health and Nutrition Examination Survey, 1988-1991. Hypertension. 1995; 25:305-313. [PubMed: 7875754]

27. Verdecchia $\mathrm{P}$, et al. Independent predictors of isolated clinic ('white-coat') hypertension. J Hypertens. 2001; 19:1015-1020. [PubMed: 11403348]

28. Messerli FH, et al. Disparate cardiovascular findings in men and women with essential hypertension. Ann Intern Med. 1987; 107:158-161. [PubMed: 3605894]

29. Pomerleau J, et al. Relationships of fasting and postload glucose levels to sex and alcohol consumption. Are American Diabetes Association criteria biased against detection of diabetes in women? Diabetes Care. 1999; 22:430-433. [PubMed: 10097924]

30. Hanefeld M, et al. Insulin secretion and insulin sensitivity pattern is different in isolated impaired glucose tolerance and impaired fasting glucose: the Risk Factor in Impaired Glucose Tolerance for Atherosclerosis and Diabetes study. Diabetes Care. 2003; 26:868-874. [PubMed: 12610051]

31. Barrett-Connor E, Ferrara A. Isolated postchallenge hyperglycemia and the risk of fatal cardiovascular disease in older women and men. The Rancho Bernardo Study. Diabetes Care. 1998; 21:1236-1239. [PubMed: 9702426]

32. Cogswell ME, et al. Medically advised, mother's personal target, and actual weight gain during pregnancy. Obstet Gynecol. 1999; 94:616-622. [PubMed: 10511369]

33. Rooney BL, Schauberger CW. Excess pregnancy weight gain and long-term obesity: one decade later. Obstet Gynecol. 2002; 100:245-252. [PubMed: 12151145]

34. Cohen A, et al. Number of children and risk of metabolic syndrome in women. J Womens Health (Larchmt). 2006; 15:763-773. [PubMed: 16910908]

35. Stuebe AM, et al. Duration of lactation and incidence of type 2 diabetes. JAMA. 2005; 294:26012610. [PubMed: 16304074]

36. Kim C, et al. Gestational diabetes and the incidence of type 2 diabetes: a systematic review. Diabetes Care. 2002; 25:1862-1868. [PubMed: 12351492]

37. Di Cianni G, et al. C-reactive protein and metabolic syndrome in women with previous gestational diabetes. Diabetes Metab Res Rev. 2007; 23:135-140. [PubMed: 16770838]

38. Lauenborg J, et al. The prevalence of the metabolic syndrome in a Danish population of women with previous gestational diabetes mellitus is threefold higher than in the general population. $\mathrm{J}$ Clin Endocrinol Metab. 2005; 90:4004-4010. [PubMed: 15840755] 
39. Noussitou P, et al. Gestational diabetes mellitus and the risk of metabolic syndrome: a populationbased study in Lausanne, Switzerland. Diabetes Metab. 2005; 31:361-369. [PubMed: 16369198]

40. Carr DB, et al. Gestational diabetes mellitus increases the risk of cardiovascular disease in women with a family history of type 2 diabetes. Diabetes Care. 2006; 29:2078-2083. [PubMed: 16936156]

41. Report of the National High Blood Pressure Education Program Working Group on high blood pressure in pregnancy. Am J Obstet Gynecol. 2000; 183:S1-S22. [No authors listed].

42. Kabiru W, Raynor BD. Obstetric outcomes associated with increase in BMI category during pregnancy. J Obstet Gynecol. 2004; 191:928-932.

43. O'Brien TE, et al. Maternal body mass index and the risk of pre-eclampsia: a systematic overview. Epidemiology. 2003; 14:368-374. [PubMed: 12859040]

44. Solomon CG, Seely EW. Hypertension in pregnancy. Endocrinol Metab Clin North Am. 2006; 35:157-171. [PubMed: 16310647]

45. Laivuori $\mathrm{H}$, et al. Hyperinsulinemia 17 years after preeclamptic first pregnancy. J Clin Endocrinol Metab. 1996; 81:2908-2911. [PubMed: 8768850]

46. Sibai BM, et al. Severe preeclampsia-eclampsia in young primigravid women: subsequent pregnancy outcome and remote prognosis. Am J Obstet Gynecol. 1986; 155:1011-1016. [PubMed: 3777042]

47. Diamanti-Kandarakis E, et al. A survey of the polycystic ovary syndrome in the Greek island of Lesbos: hormonal and metabolic profile. J Clin Endocrinol Metab. 1999; 84:4006-4011. [PubMed: 10566641]

48. Zawadzki, JK.; Dunaif, A. Diagnostic criteria for polycystic ovary syndrome: towards a rational approach. In: Dunaif, A., et al., editors. Polycystic Ovary Syndrome. Blackwell Scientific; Boston, MA: 1992. p. 377-384.

49. Rotterdam ESHRE/ASRM-Sponsored PCOS Consensus Workshop Group. Revised 2003 consensus on diagnostic criteria and long-term health risks related to polycystic ovary syndrome. Fertil Steril. 2004; 81:19-25.

50. Azziz R, et al. Positions statement: criteria for defining polycystic ovary syndrome as a predominantly hyperandrogenic syndrome: an Androgen Excess Society guideline. J Clin Endocrinol Metab. 2006; 91:4237-4245. [PubMed: 16940456]

51. Essah PA, Nestler JE. Metabolic syndrome in women with polycystic ovary syndrome. Fertil Steril. 2006; 86:S18-S19. [PubMed: 16798277]

52. Barber TM, et al. Obesity and polycystic ovary syndrome. Clin Endocrinol (Oxf). 2006; 65:137145. [PubMed: 16886951]

53. Essah PA, Nestler JE. The metabolic syndrome in polycystic ovary syndrome. J Endocrinol Invest. 2006; 29:270-280. [PubMed: 16682845]

54. Sam S, et al. Dyslipidemia and metabolic syndrome in the sisters of women with polycystic ovary syndrome. J Clin Endocrinol Metab. 2005; 90:4797-4802. [PubMed: 15899949]

55. Legro RS, et al. Prevalence and predictors of risk for type 2 diabetes mellitus and impaired glucose tolerance in polycystic ovary syndrome: a prospective, controlled study in 254 affected women. J Clin Endocrinol Metab. 1999; 84:165-169. [PubMed: 9920077]

56. Solomon, CG.; Seely, EW. Polycystic ovarian syndrome. In: Izzo, JL.; Black, HR., editors. American Heart Association. Hypertension Primer. Lippincott Williams \& Wilkins; Philadelphia, PA: in press

57. Gallo MF, et al. Combination contraceptives: effects on weight. Cochrane Database of Systematic Reviews. 2007; (issue 2) Art. No.: CD003987. DOI: 10.1002/14651858.CD003987.pub2.

58. Sabatini R, Cagiano R. Comparison profiles of cycle control, side effects and sexual satisfaction of three hormonal contraceptives. Contraception. 2006; 74:220-223. [PubMed: 16904415]

59. Coney $\mathrm{P}$, et al. Weight change and adverse event incidence with a low-dose oral contraceptive: two randomized, placebo-controlled trials. Contraception. 2001; 63:297-302. [PubMed: 11672550]

60. Vrbikova J, et al. Weight change and androgen levels during contraceptive treatment of women affected by polycystic ovary. Endocr Regul. 2006; 40:119-123. [PubMed: 17201585] 
61. Bittner V. Perspectives on dyslipidemia and coronary heart disease in women. J Am Coll Cardiol. 2005; 46:1628-1635. [PubMed: 16256860]

62. Chasan-Taber L, et al. Prospective study of oral contraceptives and hypertension among women in the United States. Circulation. 1996; 94:483-489. [PubMed: 8759093]

63. Oelkers WH. Drospirenone in combination with estrogens: for contraception and hormone replacement therapy. Climacteric. 2005; 8(Suppl 3):19-27. [PubMed: 16203652]

64. Crawford SL, et al. A longitudinal study of weight and the menopause transition: results from the Massachusetts Women's Health Study. Menopause. 2000; 7:96-104. [PubMed: 10746891]

65. Sternfeld B, et al. Menopause, physical activity, and body composition/fat distribution in midlife women. Med Sci Sports Exerc. 2005; 37:1195-1202. [PubMed: 16015138]

66. Ferrara CM, et al. Differences in adipose tissue metabolism between postmenopausal and perimenopausal women. J Clin Endocrinol Metab. 2002; 87:4166-4170. [PubMed: 12213866]

67. Carr MC. The emergence of the metabolic syndrome with menopause. J Clin Endocrinol Metab. 2003; 88:2404-2411. [PubMed: 12788835]

68. Manson JE, et al. Estrogen plus progestin and the risk of coronary heart disease. N Engl J Med. 2003; 349:523-534. [PubMed: 12904517]

69. Grady D, et al. Cardiovascular disease outcomes during 6.8 years of hormone therapy: Heart and Estrogen/progestin Replacement Study follow-up (HERS II). JAMA. 2002; 288:49-57. [PubMed: 12090862]

70. Mosca L, et al. Evidence-based guidelines for cardiovascular disease prevention in women: 2007 update. J Am Coll Cardiol. 2007; 49:1230-1250. [PubMed: 17367675]

71. Stampfer MJ, et al. Primary prevention of coronary heart disease in women through diet and lifestyle. N Engl J Med. 2000; 343:16-22. [PubMed: 10882764]

72. Mann JI. Nutrition recommendations for the treatment and prevention of type 2 diabetes and the metabolic syndrome: an evidenced-based review. Nutr Rev. 2006; 64:422-427. [PubMed: 17002238]

73. Bentley-Lewis, R.; Pendergrass, M. An exercise prescription for the metabolic syndrome. In: Fonseca, V., editor. Treatment of the Metabolic Syndrome. John Wiley and Sons; New York, NY: in press

74. SHEP Cooperative Research Group. Prevention of stroke by antihypertensive drug treatment in older persons with isolated systolic hypertension. Final results of the Systolic Hypertension in the Elderly Program (SHEP). JAMA. 1991; 265:3255-3264. [PubMed: 2046107]

75. Downs JR, et al. Primary prevention of acute coronary events with lovastatin in men and women with average cholesterol levels: results of AFCAPS/ TexCAPS. Air Force/Texas Coronary Atherosclerosis Prevention Study. JAMA. 1998; 279:1615-1622. [PubMed: 9613910]

76. Sacks FM, et al. The effect of pravastatin on coronary events after myocardial infarction in patients with average cholesterol levels. Cholesterol and Recurrent Events Trial investigators. N Engl J Med. 1996; 335:1001-1009. [PubMed: 8801446]

77. Knowler WC, et al. Reduction in the incidence of type 2 diabetes with lifestyle intervention or metformin. N Engl J Med. 2002; 346:393-403. [PubMed: 11832527]

78. Cooper WO, et al. Major congenital malformations after first-trimester exposure to ACE inhibitors. N Engl J Med. 2006; 354:2443-2451. [PubMed: 16760444]

79. Buttar HS. An overview of the influence of ACE inhibitors on fetal-placental circulation and perinatal development. Mol Cell Biochem. 1997; 176:61-71. [PubMed: 9406146]

80. Daikha-Dahmane F, et al. Foetal kidney maldevelopment in maternal use of angiotensin II type I receptor antagonists. Pediatr Nephrol. 2006; 21:729-732. [PubMed: 16565869]

81. Miller VT. Dyslipoproteinemia in women. Special considerations. Endocrinol Metab Clin North Am. 1990; 19:381-398. [PubMed: 2192879]

82. Ofori B, et al. Risk of congenital anomalies in pregnant users of statin drugs. Br J Clin Pharmacol. 2007 [doi:10.1111/j.1365-2125.2007.02905.x]. 


\section{Box 1}

\section{Gender differences in metabolic disease}

Central adiposity

Prevalence of extreme obesity is increased in women compared with men

Increased waist circumference in women increases risk of metabolic syndrome to a greater degree than in men

\section{Dyslipidemia}

Associated with a greater risk for coronary artery disease in women than in men

Elevated triglyceride levels have a greater impact on coronary artery disease risk in women than in men, especially when combined with low HDL levels

Hypertension

Congestive heart failure is more commonly seen as a consequence of hypertension in women than in men

White coat hypertension' is more commonly reported in women than in men

Hyperglycemia

Glucose levels after a glucose load are more commonly elevated than fasting blood glucose in women; the opposite is found in men 
Box 2

Unique metabolic syndrome risk factors in women

Pregnancy-related weight gain

Hormonal contraceptive use

- Polycystic ovary syndrome

- Gestational diabetes

- Preeclampsia

The menopause

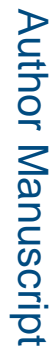

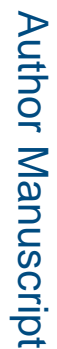

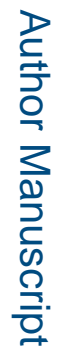

Nat Clin Pract Endocrinol Metab. Author manuscript; available in PMC 2015 May 12. 


\section{KEY POINTS}

- Cardiovascular disease is a significant cause of morbidity and mortality in women

Metabolic risk factors for cardiovascular disease risk are clustered in the metabolic syndrome

The metabolic syndrome components can be defined differently for women than for men and might have different implications for cardiovascular disease

Clinicians should be cognizant of clinical matters specific to women, such as pregnancy and its complications, lactation, polycystic ovary syndrome, the use of hormonal contraceptives, and the menopause, when considering prevention and management of the metabolic syndrome in women 


\section{REVIEW CRITERIA}

We searched for original articles that focused on the metabolic syndrome in women on PubMed and Ovid MEDLINE (published between 2000 and 2007). The search terms we used were "metabolic syndrome", "women", "obesity", "dyslipidemia", "glucose intolerance", "hypertension", "PCOS", "pregnancy", "oral contraceptive", "preeclampsia" and "menopause". All papers identified were English-language, full-text papers. We also searched the reference lists of identified articles for further papers. 
Table 1

Definition of the metabolic syndrome ${ }^{a}$ according to the National Cholesterol Education Program's Adult Treatment Panel III (2001). ${ }^{4}$

\begin{tabular}{lll}
\hline Component & Criteria for women & Criteria for men \\
\hline Waist circumference & $\geq 88 \mathrm{~cm}$ & $\geq 102 \mathrm{~cm}$ \\
Glucose control $^{b}$ & $\begin{array}{c}\text { Diabetes or fasting plasma glucose } \\
\geq 110 \mathrm{mg} / \mathrm{dl}(6.11 \mathrm{mmol} / \mathrm{l})\end{array}$ & $\begin{array}{c}\text { Diabetes or fasting plasma glucose } \\
\geq 110 \mathrm{mg} / \mathrm{dl}(6.11 \mathrm{mmol} / \mathrm{l})\end{array}$ \\
Blood lipid levels & & \\
HDL & $<50 \mathrm{mg} / \mathrm{dl}(1.30 \mathrm{mmol} / \mathrm{l})$ & $<40 \mathrm{mg} / \mathrm{dl}(1.04 \mathrm{mmol} / \mathrm{l})$ \\
Triglycerides & $\geq 150 \mathrm{mg} / \mathrm{dl}(1.70 \mathrm{mmol} / \mathrm{l})$ & $\geq 150 \mathrm{mg} / \mathrm{dl}(1.70 \mathrm{mmol} / \mathrm{l})$ \\
Blood pressure & $\geq 130 / 85 \mathrm{mmHg}$ & $\geq 130 / 85 \mathrm{mmHg}$ \\
\hline
\end{tabular}

${ }^{a}$ A diagnosis of metabolic syndrome requires the presence of three or more components.

${ }^{b}$ Revised ATP III criteria include fasting plasma glucose level $\geq 100 \mathrm{mg} / \mathrm{dl}(5.55 \mathrm{mmol} / \mathrm{l}){ }^{5}$ 